\begin{tabular}{ll}
\hline & $\begin{array}{l}\text { Kastamonu Eğitim Dergisi } \\
\text { Kastamonu Education Journal }\end{array}$ \\
$\begin{array}{l}\text { Ocak 2019 Cilt:27 Sayı:1 } \\
\text { kefdergi.kastamonu.edu.tr }\end{array}$ & Başuru Tarihi/Received: 10.11 .2017 \\
Kabul Tarihi/Accepted: 27.12.2017 & Dol: $10.24106 /$ kefdergi.2360 \\
\hline
\end{tabular}

\title{
Sınıf Öğretmeni Adaylarının Problem Çözme Sürecinde Kullandıkları Stratejiler: Rutin Problem Çözme Durumları
}

\section{The Strategies Used by Prospective Primary School Teachers in the Process of Problem Solving: The Case of Routine Problem Solving}

\section{Öz}

\author{
Rezan YILMAZ2
}

Yapılan çalışma genel anlamda, sınıf öğretmeni adaylarııı problem çözme süreçleri ile ilgili durumlarını ortaya koymayı hedeflemekle beraber özelde, problem çözme sürecinde kullandıkları stratejilerin belirlenmesi amaçlamaktadır. Çalışma, bir devlet üniversitesinin eğitim fakültesi sınıf öğretmenliği ana bilim dalı üçüncü sınıfında öğrenim gören 126 katılımcı ile nitel olarak gerçekleştirilmiştir. Kendilerine sorulan ilkokul düzeyine uygun rutin bir problemin çözümünün incelenmesi ile elde edilen veriler Polya'nın problem çözme sürecinin basamakları doğrultusunda betimsel olarak analiz edilmiştir. Elde edilen sonuçlar, sınıf öğretmeni adaylarının çoğunlukla tahmin-kontrol, sistematik liste yapma ve ilkokul düzeyine uygun olmayan denklem kullanma stratejisini kullandıklarını, bir kısmının ise muhakeme etme ve diyagram kullanma stratejilerini tercih ettiklerini göstermektedir.

Anahtar Kelimeler: Matematik eğitimi, problem çözme, problem çözme stratejisi, sınıf öğretmeni adayı

\section{Abstract}

The study is aimed to reveal the statuses of prospective primary school teachers relevant to problem solving processes in general sense, it is actually aiming to determine the strategies they use in this process. The study had been realized qualitatively by 126 participants studying at third grade of primary school teaching department of a state university's faculty of education. The data, obtained through the examination of the solution of a routine problem in primary school level directed to them, has been analyzed descriptively under stages by the problem solving process of Polya. The results indicate that they are generally using the strategies of guessing and checking, systematic listing and using equations and sometimes they prefer reasoning and using diagrams.

Keywords: Mathematics education, problem solving, problem solving strategies, prospective primary school teacher

1. Makalenin bir kısmı ICEMST-2016 da sözlü bildiri olarak sunulmuştur.

2. Ondokuz Mayıs Üniversitesi, Eğitim Fakültesi, Matematik ve Fen Bilimleri Eğitimi Bölümü, Samsun, Türkiye; https://orcid.org/0000-0003-4835-2630

Atıf / Citation: Yılmaz, R. (2019). Sınıf öğretmeni adaylarının problem çözme sürecinde kullandıkları stratejiler: rutin problem çözme durumları.Kastamonu Education Journal, 27(1), 85-94. doi:10.24106/kefdergi.2360 


\section{Extended Abstract}

Introduction: Today, in many countries, skills such as "problem solving, reasoning, connecting and communicating" are coming to the forefront among the skills intended to be brought in the education process (NCTM, 1991). And in Turkey, along with the developments realized in 2005 having the quality of reform, curriculums which intend to bring similar skills are being applied (MEB, 2015; 2017). Therefore, it has been expected for these skills to be spread in the whole mathematics education, and they have been addressed as a process that the teachers are required to structure in their professional competences (MEB, 2008; NCTM, 1991). It is being observed that problem solving is coming to the forefront among these skills that are being intended to be brought.

Problem solving has been divided to various stages by Polya (1957): understanding the problem, devising a plan, carrying out the plan, and looking back. Some of the strategies being used in problem solving process are as follows: systematic listing, guessing and checking, drawing diagrams, looking for a pattern, simplifying the problem, using equation, working backwards, making table, reasoning and using model (Altun 2010; Fan and Zhu, 2007; Polya, 1957).

When the role of teachers and thus of the prospective teachers is considered in attainment of this skill by the students, the availability of teachers and prospective teachers having the required competences is very important. In this sense, it is required to investigate the competences of prospective primary school teachers who will be providing this skill being among the attainments as from first grade of primary school. In general, the study purposes to reveal the statuses of prospective primary school teachers relevant to problem solving processes and it is actually focusing to determine the strategies they use in this process. In this sense, the problem sentence of the study has been addressed as "Which strategies are the prospective primary school teachers using in the (routine) problem solving processes?"

Method: This is a qualitative study realized on 126 prospective primary school teachers studying their third grade at a state university's faculty of education in Black Sea Region in the autumn period of 2015-2016, and a case study was conducted to examine the solutions developed by the prospective teachers for the problem and the strategies they use (Yin, 2003). The issues of problem, types of problem and problem solving process -that they were encountering within the scope of Mathematics Education -I course that was being taught in the then current period- had been stated to the prospective teachers. By the end of about twelve hours process, it had been asked for all the prospective teachers getting the course to solve a routine problem considering the problem solving stages. And then, descriptive analysis of the data -obtained as written document- had been realized by two individuals being specialized in their field (Berg, 2001; Yıldırım and Şimsek, 2006).

Results: When the solutions were examined, 113 of prospective teachers had obtained a correct solution. During the devising a plan stage, 99 of them (87.61\%) had selected a strategy, and 14 of them (12.39\%) had not selected a strategy. $33(29.20 \%)$ of the selected strategies had been named as guessing and checking, $22(19.47 \%)$ as systematic listing, $20(17.70 \%)$ as drawing diagram, 9 (7.97\%) as reasoning, $9(7.97)$ as guessing, $5(4.42 \%)$ as using equation, $1(0.88 \%)$ as looking for a pattern. During the looking back stage, 27 (23.89\%) of them had implemented their strategies correct by determining a different strategy, and 14 of them (12.39\%) had implemented a different strategy despite not having determined any strategy. And the other $72(63.72 \%)$ of them had not provided any different solution suggestion in the stage of looking back. When the solutions of 41 of them $(36.28 \%)$ implementing the second solution had been examined, 13 of the implemented strategies (11.50\%) were as guessing and checking, $9(7.96 \%)$ as using equation, $9(7.96 \%)$ as reasoning, $8(7.08 \%)$ as systematic listing, and $2(1.77 \%)$ as drawing diagram. When the implemented strategies are examined, it is being observed that the use of strategy of using equation had increased along with showing similarity to the strategies implemented for the first solution.

Discussion and Conclusion: The results obtained from the study are showing that the majority of prospective teachers were determining a strategy for a routine problem, and that they were implementing their determined or different strategy. And in the stage of looking back, less than half of them could be able to suggest a second solution by using a different strategy. One of the significant results obtained from the study is that a few of the prospective teachers were using the strategy of making use of equations in their first solution considering that they will be practicing as primary school teachers and that their students will be ones being in the period of concrete operational stage during their cognitive development. But it is being observed that the frequency of using an equation was increasing when a second solution was requested. It can be thought that this condition is arising from the fact that they were unable to determine a strategy which would anticipate a different solution. Moreover, in some of their solutions, they had tried to rename the strategy as visualizing the unknown elements of the equation by concrete objects in the sake of preferring not to use an equation. When the strategies used are considered, it is being observed that they are mostly ones frequently being referred in literature such as guessing and checking, systematic listing and drawing diagram.

In the light of the obtained results, it is being considered that overcoming the deficiencies of prospective teachers in learning new and different strategies, increasing their education regarding the use of strategies relevant to primary school students, and giving opportunities for them to encounter different problems will provide significant contribution to the problem solving processes of prospective primary school teachers. 


\section{Giriş}

Dünyada matematik reformunun şekillenmesiyle birçok ülkenin öğretim programlarında "problem çözme, muhakeme etme, ilişkilendirme ve iletişim kurma" becerileri önemli hale gelmiştir (National Council of Teachers of Mathematics [NCTM], 1991). Bu becerilerin matematik öğretiminin tamamına yayılması beklenmiş ve yine bu beceriler, matematik öğretmenlerinin mesleki yeterliklerinde de biçimlendirmeleri gereken bir süreç olarak ele alınmıştir (NCTM, 1991; Milli Eğitim Bakanlığı [MEB], 2008; 2015; 2017). Bu becerilerden problem çözme ise kazandırılması hedeflenen becerilerin başında gelmektedir.

Problem, genel olarak kişinin ilk kez karşılaştığı ve çözme intiyacı duyduğu, çözüm için hazır bir yolun bilinmediği ancak kendi bilgi ve becerileri ile çözebileceği durumdur. Problem çözme ise, bilinmeyen veya çözümü açık olmayan bu durumu ortadan kaldırmak için gerekli olanı yapmanın karmaşık sürecidir (Altun 2010; Jonassen, 2000; Krulik ve Rudnik, 1988; NCTM, 2000; Olkun ve Toluk, 2009; Posamentier ve Krulik, 2008). Problemler genel olarak rutin (sıradan) ve rutin olmayan (sıra dışı) problemler olarak ikiye ayrılır: Rutin problemler sıkça karşılaşılan, ders kitaplarında daha çok yer alan ve dört işlem gerektiren problemler olarak bilinirler. Rutin olmayan problemler ise, rutin problemlere göre daha az karşılaşılan ve çözümü üzerinde daha farklı düşünmeler gerektiren problemlerdir (Altun, 2010; Gürbüz ve Güder, 2016). Süreç, daha iyi anlaşılması için çeşitli aşamalara ayrılmıştır ve literatürdeki en yaygın kabul gören aşamalandırma, Polya (1957) tarafindan yapılmıştır:

Problemi anlama, problem ile verilenlerin, istenilenlerin ve varsa koşulların tam olarak ifade edilmesidir.

Planlama yapma, problemin çözümü için kullanılacak olan uygun stratejinin bazı sorular sorularak belirlenmesidir.

Planı uygulama, belirlenen stratejinin uygulanarak problemin çözülmesidir. Eğer problem çözülemez ise birinci ve ikinci aşamaların eksikliği veya yanlışlığı kontrol edilir. Yine çözülemez ise strateji değiştirilir.

Geriye dönme (çözümün değerlendirilmesi), problemin çözüm sonrası değerlendirilmesi, elde edilen sonuçların kontrolünün yapılıp başka çözüm yolunun olup olmadığının tartı̧ılması ve farklı problemler üzerinden değerlendirmeler yapılmasıdır.

Problem çözme stratejileri, kişinin bir problemin çözümü sürecinde ortaya koyduğu bilişsel aktivitelerin her biridir (Altun, Memnun, Yazgan; 2007). Bu stratejileri bilmek, kişinin problemleri doğru çözmesini garantilemez fakat doğru ve sistematik girişimlerde bulunmasına neden olur ve doğru çözüme ulaşma ihtimalini artırır (Cai, 2003). Problem çözme stratejilerinden bazıları ise aşağıdaki gibi verilebilir (Altun 2010; Fan ve Zhu, 2007; Polya, 1957):

Sistematik liste yapma; mümkün olan bütün durumların bilinmesi için dikkatle seçilmiş bir sırayla liste yapılır.

Tahmin ve kontrol; mantıklı bir tahmin yapıp doğruluğu araştırılır. Tahmin eğer doğru cevap ise problemin çözümüdür, değilse önceki tahminin katkısıyla başka bir tahmin yapılır.

Diyagram çizme; problemi görsel olarak sunmak için bilgiye dayalı bir çizim yapılır.

Bağıntı bulma (Örüntü arama); problemdeki sayılar ve şekillerle ilgili ortak özellik, değişim, farklılıklara dayalı bir bağınt (örüntü) oluşturulur.

Benzer basit problemlerden yararlanma; orijinal probleme benzer ve sayısal verileri küçük olan başka problemler çözülür ve orijinal problemin çözümü basitleştirilir.

Denklem kurma; bilinmeyen yerine değerler konularak çözüm bulunur.

Geriye doğru çalışma; sonuçtan hareket edilip işlemleri tersine çevirerek adım adım ilk bilgilere ulaşıır.

Tablo yapma; veriler ya da çözüm sırasında elde edilen bilgiler bir tablo halinde düzenlenir ve ilişkilendirilir.

Muhakeme etme; çözüme ulaşmak için doğru olan durumdan yola çıkarak diğer durumların doğruluğu gösterilir.

Model oluşturma; çokluklar, ilişkiler ya da değişikliklerdeki bilgileri modellemek için görseller kullanılır.

Öğretmen eğitimi ile ilgili yapılan çalışmalar incelendiğinde, öğretmenlerin ve öğretmen adaylarının nası öğrendikleri ve profesyonelce geliştikleri sorusu uzun yıllardır araştırmacıları meşgul etmektedir (Hammerness, Darling-Hammond ve Bransford, 2005). Öğrencilerine öğretim programlarının hedeflediği becerileri kazandırmada öğretmenlerin, dolayısı ile öğretmen adaylarına rolü büyüktür. Bu nedenle, öğretmen adaylarının gerekli yeterliklere sahip olması fazlasıyla önemlidir. Ancak, öğretmenlerin ve öğretmen adaylarının problem çözmeleri üzerine yapılmış çalışmalar çok azdır 
(English, Jones, Tirosh, Lesh ve Bartolini Bussi, 2002).

Türkiye'de öğretmen ve öğretmen adaylarının problem çözme süreçleri ile ilgili yapılan çalışmalar incelendiğinde, çoğunluğunun ilköğretim ve ortaöğretim matematik öğretmen ve öğretmen adayları ile yapıldığı görülmüştür. Örneğin Pehlivan (2011), ortaöğretim matematik öğretmen adayları ile yaptığı çalışmada problem çözümlerinde kullanılan çözüm yollarını, oluşan çözüm uzaylarını, ortaya çıkan bilgi türlerini, kullanılan stratejileri ve gösterim şekillerini araştrrmıştr. Kullanılan stratejilerle ilgili sonuçlar şekil çizme, formül kullanma, diyagram çizme ve örüntü arama şeklindedir. Avcu (2012), ilköğretim matematik öğretmen adaylarının problem çözme süreçlerini farklı sınıf seviyelerine göre incelemiş, en çok kullanılan stratejilerin ise tahmin-kontrol ve şekil çizme olduğunu söylemiştir. Gürbüz ve Güder (2016) ortaokul matematik öğretmenlerinin rutin olmayan problem çözümünde kullandıkları stratejilerin belirlendiği çalışmalarında, öğretmenlerin problemlerin doğru sonucunu bulmada kısmen yeterli oldukları, fakat farklı stratejiler kullanmada yetersiz oldukları sonucuna varmışlardır. Gümüş ve Umay (2017), problem çözme stratejileri öğretiminin ilköğretim matematik öğretmen adaylarının kavramsal/işlemsel çözüm tercihlerine ve problem çözme performansına etkisini inceledikleri çalışmalarında, strateji temelli problem çözme eğitimi alan grubun işlemsel çözüm yollarını, diğer grubun ise kavramsal çözüm yollarını tercih ettiklerini göstermişlerdir. Sınıf öğretmenliği ile ilgili yapılan çalışmalar incelendiğinde ise, Altun, Memnun ve Yazgan (2007) sınıf öğretmeni adaylarının rutin olmayan problemleri çözme becerilerini deneysel bir çalışma ile araştırmışlar ve katılımcıların problem çözme ve strateji öğretimi içerikli eğitimi sonucunda, eğitimin strateji öğrenmede etkili olduğu ve bunun problem çözme başarısını yükselttiği sonucuna ulaşmışlardır. Ulu (2008), sınıf öğretmeni, sınıf öğretmeni adayı ve 5. sınıf öğrencileri ile yaptığı çalışmada, problem çözme stratejilerinde anlamlı farklılıklar olduğunu göstermiş ve sınıf öğretmeni adaylarının denklem kullanma stratejisini kullanmaya eğilimli olduklarını söylemiştir. Kılıç (2014), sınıf öğretmenlerinin problem kurmayı algılayış biçimlerini incelediği çalışmada, öğretmenlerin problem kurma ile ilgili algılarının farklııık gösterdiği belirlenmiştir. Aylar (2017), sınıf öğretmeni adaylarının problem çözmeye dair pedagojik alan bilgilerini önce teorik, sonra uygulama düzeyinde incelediği çalışmasında ise, bir kısmında problem çözmeye dair güncel bir pedagojik alan bilgisinin olmadığından, diğerlerinin ise problem çözmeye dayalı bir derse ilişkin teorik bilgileri ile uygulamaları arasında önemli bir fark gözlendiğinden bahsetmiştir.

Milli Eğitim Bakanlığı [MEB] İlkokul Matematik Dersi Öğretim Programı incelendiğinde, geliştirilmesi amaçlanan temel becerilerin başında 'problem çözme'nin geldiği ve 1. sınıftan itibaren kazanımların içerisinde olduğu görülmektedir. (MEB, 2015; 2017). Dolayısı ile, bu becerinin kazandırılmasında birinci derecede sorumlu olacak sınıf öğretmeni adaylarına büyük iş düşmektedir. Ayrıca, somut işlem döneminde olan ilkokul öğrencilerinin bilişsel gelişim düzeyi olarak ortaokul ve lise öğrencilerine göre farklı oldukları da düşünüldüğünde, sınıf öğretmen adaylarının problem çözmeleri ile ilgili yapılacak çalışmalar, bu anlamdaki yeterlikleri hakkında da fikir verecek ve problem çözme öğretimindeki eksiklikleri gidermede yararlı olabilecektir. Yapılan çalışmaların sınırlı sayıda olduğu da dikkate alındığında sınıf öğretmeni adaylarııı problem çözme süreçleri ve kullandıkları stratejilerin araştııımasının, alandaki eksiği kapatmada önemli olduğu düşünülmektedir.

\section{Araştırmanın amacı}

Çalışma genel anlamda sınıf öğretmeni adaylarının problem çözme süreçlerini incelemeyi hedeflemekle beraber, özel olarak problem çözme sürecinde kullandıkları stratejileri belirlemeyi amaçlamaktadır.

\section{Araştırmanın problemi}

Çalışmanın genel anlamdaki problem cümlesi, "eğitim fakültesi sınıf öğretmenliği öğretmen adayları (rutin) problem çözme süreçlerinde hangi stratejileri kullanmaktadır?" olarak ele alınmıştır. Bunun için aşağıdaki alt problemlere cevap aranmıştır:

- Sınıf öğretmeni adaylarının (rutin) problem çözerken "planlama yapma" aşamasında seçtikleri stratejiler nelerdir ve "planı uygulama" aşamasında bu stratejileri nasıl uygulamaktadırlar?

- S Sınıf öğretmeni adaylarının (rutin) problem çözerken "geriye dönme (çözümü değerlendirme)" aşamasında yeni çözüm için seçtikleri stratejiler nelerdir ve bu stratejileri nasıl uygulamaktadırlar?

\section{Yöntem}

\section{Araştırmanın modeli}

Çalışma 2015-2016 güz döneminde Karadeniz Bölgesinin bir devlet üniversitesinde öğrenim gören sınıf öğretmeni adayları üzerinde gerçekleştirilmiş nitel bir araştırmadır. Araştırmada, öğretmen adaylarının problem çözümü için geliştirdikleri çözüm yolları ve kullandıkları stratejiler ayrıntılı şekilde incelendiği için durum çalışması deseninden yararla- 
nılmıştır (Yıldırım ve Şimşek, 2006; Yin, 2003).

\section{Katilımcılar}

Çalışmaya, üniversitenin eğitim fakültesi sınıf öğretmenliği bölümünde öğrenim gören 84'ü kız, 42'si erkek toplam 126 üçüncü sınıf öğretmen adayı katıımıştır. Katılımcılar daha önceki dönemlerde, matematik öğretimine temel teşkil eden Matematik I-II dersini başarı ile tamamlamışlardır. Çalışmanın yapııdığı süreçte ise, iki şubede haftada üç saatlik Matematik Öğretimi I dersini almaktadırlar.

\section{Veri Toplama}

Öğretmen adaylarına aldıkları ders kapsamında problem, problem çeşitleri (rutin-rutin olmayan), problem çözme süreci, aşamaları ve kullanılan stratejiler anlatılmış ve (rutin ve rutin olmayan) birçok problem çözümü problem çözme aşamalarına göre gerçekleştirmiştir. Ayrıca, çözüm için seçilen stratejiler ve bu stratejilerin kullanımına odaklanılarak problem çözme süreci irdelenmiştir. Yaklaşık on iki saatlik süreç sonunda tüm adaylara somut işlem dönemi çocuğuna uygun olan şu rutin problem sorulmuştur:

"Kenan ve Nilüfer'in yaşları toplamı 22 dir. 5 yıl sonra Kenan’ın yaşı Nilüfer'in yaşının 3 katı olacağına göre Kenan'ın şimdiki yaşı kaçtır?"

Öğretmen adaylarından bu problemi, problem çözme aşamalarını dikkate alarak çözmeleri istenmiştir. Buradaki amaç, süreçte yer alan planlama yapma ve planı uygulama aşamalarını dikkate alarak farklı çözüm yollarını daha iyi yorumlayabilmek, ayrıca değerlendirme aşamasında önerilen farklı strateji ve çözüm yollarını irdeleyebilmektir. Katılımcılara yeterli süre verilmiş, isimlerinin herhangi bir yerde paylaşılmayacağı ve yapılan çözümlerin notla değerlendirilmeyeceği vurgulanmıştır. Ayrıca problemi, aşamalarına ayırarak çözmeleri konusunda uyarılar yapılmıştır.

\section{Verilerin Analizi}

Çalışmada, öğretmen adaylarının kullandıkları stratejilerin neler olduğunu belirlemek ve bu stratejileri nasıl kullandıklarını ortaya koymak amacıyla betimsel analiz yapılmıştır. Yazılı doküman şeklinde elde edilen veriler öncelikle ÖA1, ..., ÖA126 şeklinde isimlendirilmiştir. Sonrasında çözümler, alanında uzman iki kişi tarafindan bireysel olarak doğru, yanIış ve boş şeklinde üç kategoride sınıflandırılmıştı. Daha sonra ise, problem çözme basamaklarıyla ilgili kuramsal çerçeveye dayalı olarak belirlenen temalara göre kodlamalar yapılmıştr. Bu süreçte, çözümü doğru gerçekleştiren adayların öncelikle planlama yapma basamağında strateji belirleme durumlarına göre kodlamalar yapıımıştır. Sonrasında planı uygulama basamağında belirledikleri stratejinin uygulanma durumlarına göre kodlamaya devam edilmiş, daha sonra ise çözümü değerlendirme (geriye dönme) basamağında yeni çözüm için farklı bir strateji belirleme ve bunu uygulama durumlarına göre kodlama yapılmıştr. Analiz sürecindeki uzman mutabakatının ardından ilgili kategoriler belirlenmiştir (Berg, 2001; Yıldırım ve Şimşek, 2006). Ayrıca, kategorilere ait frekanslar ve yüzdeler verilerek analizin nicel olarak desteklenmesiyle araştırmanın güvenirliği artırılmaya çalışılmıştır.

\section{Bulgular ve Yorumlar}

Öğretmen adaylarının çözümleri incelendiğinde, 5'i çözüm yapmamış, 8'i ise problemi doğru anladıkları halde yanlış çözüm yapmış ve yanlış sonuç elde etmişlerdir. Diğer 113 öğretmen adayı ise bir strateji seçimi yaparak bunu uygulamış ve doğru sonuç elde etmiştir. Tablo 1'de çözümü doğru yapan adayların strateji seçimleri ve bunları uygulamaları ile ilgili frekans ve yüzde dağılımları verilmektedir.

Tablo 1. Öğretmen Adaylarının Problem Çözümündeki Strateji Seçimleri ve Uygulamaları ile ilgili Frekans ve Yüzdeler

\begin{tabular}{|c|c|c|c|c|c|}
\hline \multirow{3}{*}{ Planlama basamağı } & \multirow{3}{*}{ Planı uygulama basamağı } & \multicolumn{3}{|c|}{ Geriye dönme (çözümü değerlendirme) basamağı } & \multirow{3}{*}{ Toplam } \\
\hline & & \multicolumn{2}{|c|}{ Yeni çözüm yapan } & \multirow{2}{*}{ Yeni çözüm yapmayan } & \\
\hline & & Strateji seçen & Strateji seçmeyen & & \\
\hline \multirow{2}{*}{ Strateji seçen } & $\begin{array}{l}\text { Seçilenden farklı } \\
\text { strateji uygulayan }\end{array}$ & $\begin{array}{c}9 \\
(\% 7,96)\end{array}$ & $\begin{array}{c}7 \\
(\% 6,19)\end{array}$ & $\begin{array}{c}22 \\
(\% 19,47)\end{array}$ & $\begin{array}{c}38 \\
(\% 33,63)\end{array}$ \\
\hline & $\begin{array}{l}\text { Seçilen stratejiyi } \\
\text { uygulayan }\end{array}$ & $\begin{array}{c}16 \\
(\% 14,16)\end{array}$ & $\begin{array}{c}7 \\
(\% 6,19)\end{array}$ & $\begin{array}{c}38 \\
(\% 33,63)\end{array}$ & $\begin{array}{c}61 \\
(\% 53,98)\end{array}$ \\
\hline Strateji seçmeyen & $\begin{array}{l}\text { Herhangi bir strateji } \\
\text { uygulayan }\end{array}$ & $\begin{array}{c}2 \\
(\% 1,77)\end{array}$ & $\begin{array}{c}0 \\
(\% 0)\end{array}$ & $\begin{array}{c}12 \\
(\% 10,62)\end{array}$ & $\begin{array}{c}14 \\
(\% 12,39)\end{array}$ \\
\hline
\end{tabular}




\begin{tabular}{|c|c|c|c|c|}
\hline \multirow{3}{*}{ Planlama basamağı Planı uygulama basamağı } & \multicolumn{3}{|c|}{ Geriye dönme (çözümü değerlendirme) basamağı } & \multirow{3}{*}{ Toplam } \\
\hline & \multicolumn{2}{|c|}{ Yeni çözüm yapan } & \multirow{2}{*}{ Yeni çözüm yapmayan } & \\
\hline & Strateji seçen & Strateji seçmeyen & & \\
\hline Toplam & $\begin{array}{c}27 \\
(\% 23,89)\end{array}$ & $\begin{array}{c}14 \\
(\% 12,39)\end{array}$ & $\begin{array}{c}72 \\
(\% 63,72)\end{array}$ & $\begin{array}{c}113 \\
(\% 100) \\
\end{array}$ \\
\hline
\end{tabular}

\section{Planlama Yapma Aşamasında Seçilen Stratejiler ve Planın Uygulanması Aşamasında Bunların Kullanımı ile İlgili Bulgular}

Öğretmen adayların planlama yapma aşamaları incelendiğinde, 99'u $(\% 87,61)$ strateji belirlemiş, 14'ü $(\% 12,39)$ ise belirlememiştir. Belirlenen stratejilerin ise 33'ü $(\% 29,20)$ tahmin ve kontrol, 22'si $(\% 19,47)$ sistematik liste yapma, 20'si $(\% 17,70)$ diyagram çizme, 9'u $(\% 7,97)$ muhakeme etme, 9'u $(\% 7,97)$ tahmin, 5'i $(\% 4,42)$ denklem kullanma, 1'i $(\% 0,88)$ bağınt elde etme şeklinde isimlendirilmiştir. Planı uygulama aşamalarında ise $61^{\prime} i(\% 53,98)$ belirledikleri stratejiyi doğru uygulamış, 38'i $(\% 33,63)$ belirledikleri strateji dışında bir stratejiyi doğru uygulamış, 14'ü $(\% 12,39)$ ise herhangi bir strateji belirlemeden doğru çözüm yapmıştr.

Aşağıda, adayların seçimleri ve bunu çözüme uygulamaları ile ilgili örnekler verilmektedir. Şekil 1'de 29.öğretmen adayına (ÖA29) ait çözüm, Şekil 2'de ise 122. öğretmen adayının (ÖA122) çözümü verilmektedir:

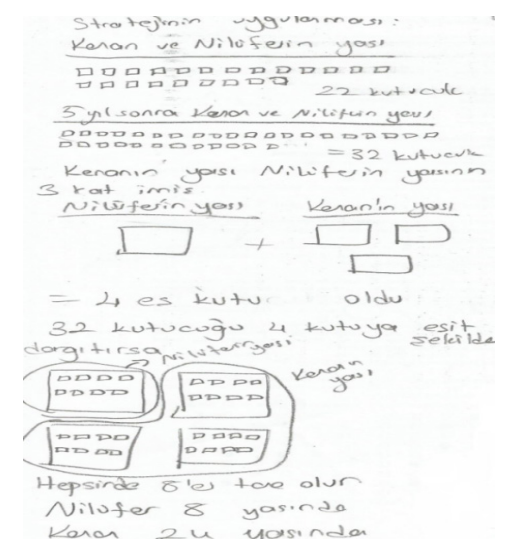

Şekil 1. ÖA29'un çözümü

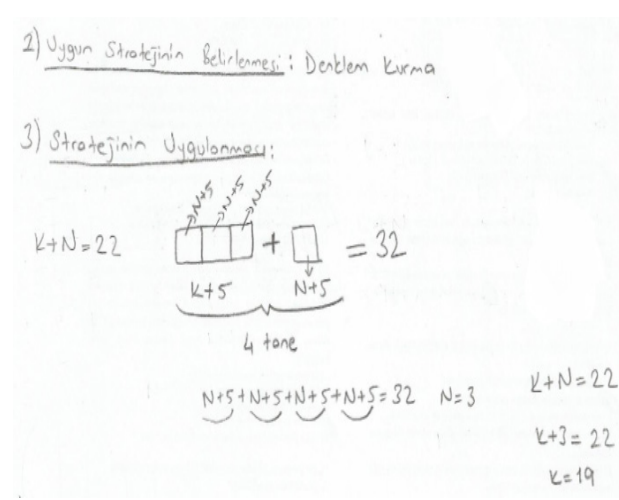

Şekil 2. ÖA122'nin çözümü

Şekil 1'de öğretmen adayı, strateji olarak muhakeme etmeyi seçmiş, stratejiye uygun çözümünü görsellerle desteklemiş ve doğru sonucu bulmuştur. Şekil 2'deki öğretmen adayı ise denklem kurma stratejisini seçmiş ve stratejiye uygun çözümünü görsellerle desteklemiştir. Şekil 3'te 101. öğretmen adayının (ÖA101) çözümü verilmektedir:

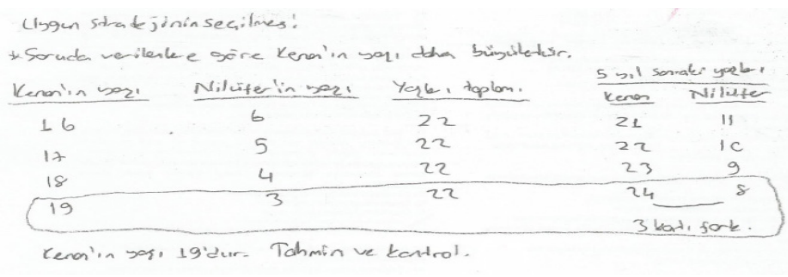

Şekil 3. ÖA101'in çözümü

Yapılan çözümde öğretmen adayının, tahmin ve kontrol stratejisini seçtiği ve çözümüne doğru uyguladığı görülmektedir. Şekil 4'de ise 96. öğretmen adayının (ÖA96) çözümü yer almaktadır: 


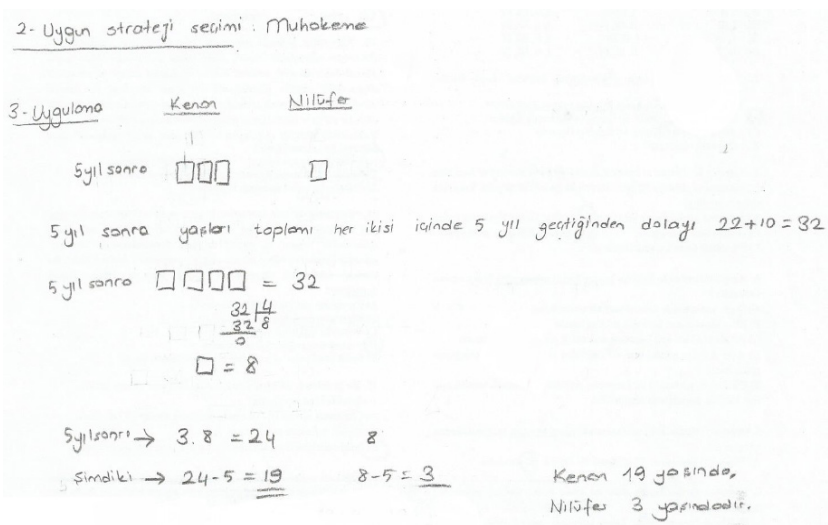

Şekil 4. ÖA96’nın çözümü

Çözüm incelendiğinde öğretmen adayının muhakeme etme stratejisini seçerek çözümüne doğru şekilde uyguladığı görülmektedir. 89. öğretmen adayına (ÖA89) ait çözüm ise aşağıda Şekil 5'teki gibidir:

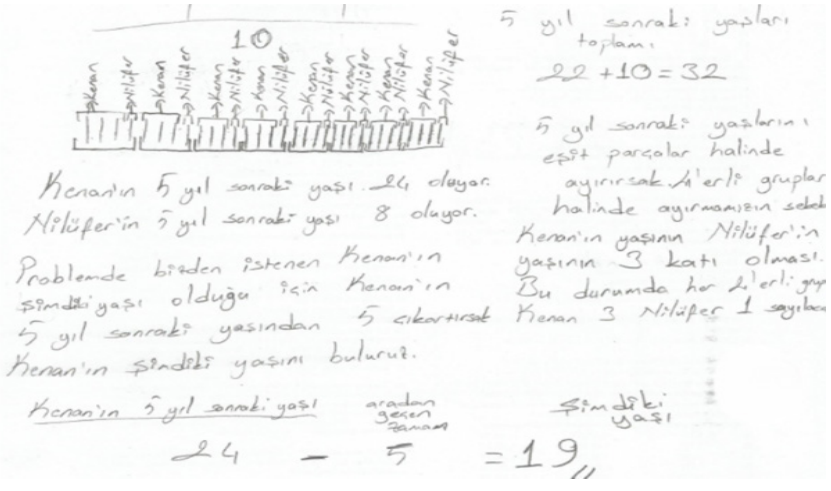

Şekil 5. ÖA89'un çözümü

Öğretmen adayının çözümü incelendiğinde, çözüm sürecinde strateji ismini belirtmediği ancak çözümde diyagram çizme stratejisini uyguladığı görülmektedir. 82. öğretmen adayı (ÖA82) ise çözümünü Şekil 6'daki gibi yapmıştır:

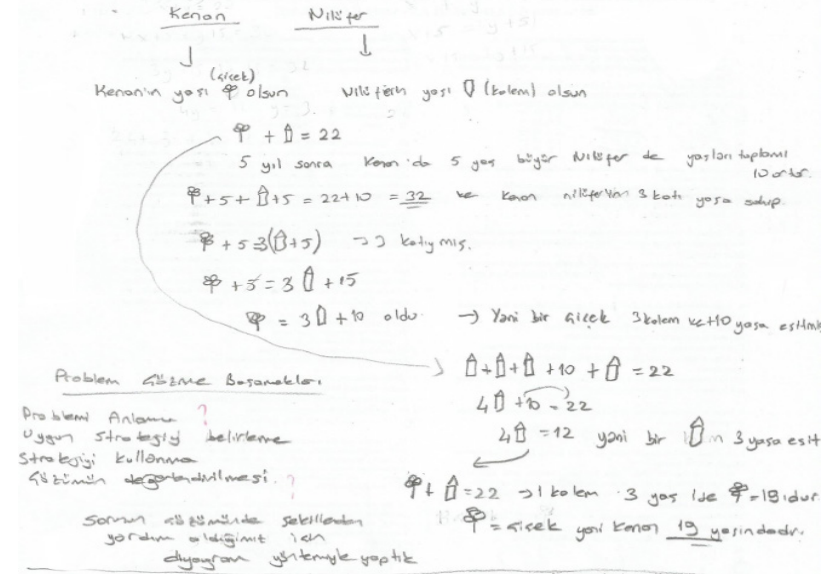

Şekil 6. ÖA82'nin çözümü

Öğretmen adayı uygun strateji olarak diyagram çizmekten bahsetmesine rağmen, uyguladığı çözüm incelendiğinde stratejisinin aslında denklem kurma olduğu görülmektedir. Öğretmen adayı çözümünde denklemleri kullanırken değişkenler yerine çiçek ve kalem resimlerini çizerek bu şekilde diyagramlardan yararlandığını düşünmüştür. Bu düşüncesi, strateji ile ilgili yanlı̧̧ yorum yapmasına neden olmuştur. Şekil 7'de ise 61.öğretmen adayının (ÖA61) çözümü yer almaktadır: 


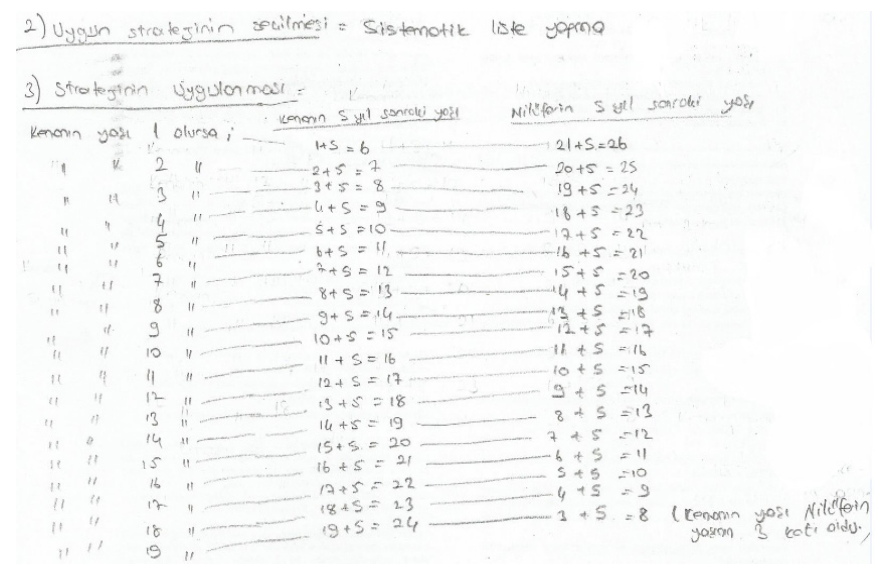

Şekil 7. ÖA6'in çözümü

Çözüm incelendiğinde, öğretmen adayının sistematik liste yapma stratejisini seçtiği ve bunu uyguladığı anlaşımaktadır. Ancak problemdeki 'Kenan'ın yaşının Nilüfer'in yaşının 3 katı olacağı' bilgisini dikkate almayıp listeyi oluştururken gereksiz hesaplamalarda bulunmuştur. Aşağıda Şekil 8'de verilen 52. öğretmen adayına (ÖA52) ait çözüm örneği, yukarıda verilen öğretmen adayının çözümüne benzemektedir. Öğretmen adayının stratejisini belirtmediği çözümü incelendiğinde, problemin verilerinin dikkatli değerlendirildiği ve gereksiz hesaplamalardan kaçınıldığı görülmektedir. 58.öğretmen adayı (ÖA58) ise Şekil 9'da, uygun strateji olarak tahmin stratejisini belirtmesine rağmen doğru olan çözümü incelendiğinde, stratejisinin tahmin-kontrol olduğu görülmektedir.

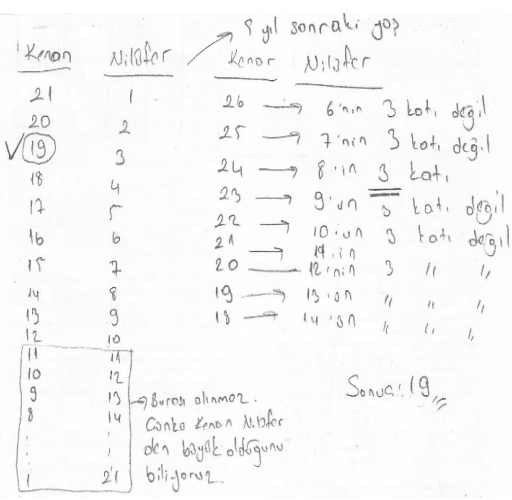

Şekil 8. ÖA52'nin çözümü

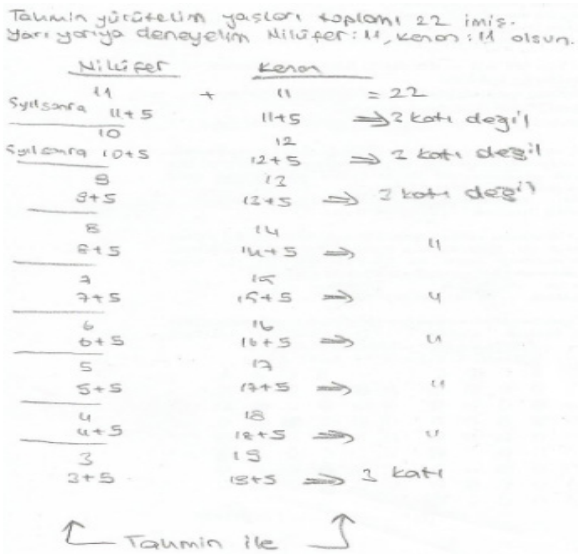

Şekil 9. ÖA58'in çözümü

\section{Çözümün Değerlendirilmesi Aşamasında Seçilen Stratejiler ve Bunların Uygulanması ile İlgili Bulgular}

Öğretmen adayları çözümlerini değerlendirirken, problem için farklı çözüm yolları geliştirmişlerdir. Adayların çözümleri incelendiğinde, 113 doğru çözüm yapan öğretmen adayından 27 'si $(\% 23,89)$ farklı strateji belirleyerek stratejilerini doğru uygulamış, 14'ü $(\% 12,39)$ ise herhangi bir strateji adı belirlememesine rağmen farklı bir strateji uygulamıştır. Diğer $72(\% 63,72)$ aday ise çözümün değerlendirilmesi aşamasında herhangi farklı bir çözüm önerisi getirmemişlerdir.

İkinci çözümü uygulayan $41(\% 36,28)$ öğretmen adayının çözümleri incelendiğinde uyguladıkları stratejilerin 13 'ü $(\% 11,50)$ tahmin-kontrol, 9'u $(\% 7,96)$ denklem kurma, 9'u $(\% 7,96)$ muhakeme etme, 8'i $(\% 7,08)$ sistematik liste yapma, 2'si $(\% 1,77)$ ise diyagram çizme şeklinde olduğu ortaya çıkmıştr. Uygulanan stratejiler incelendiğinde ilk çözüme uygulanan stratejilere benzerlik göstermekle beraber denklem kullanma stratejisinin kullanımının arttı̆ı görülmektedir.

\section{Tartışma, Sonuç ve Öneriler}

Yapılan çalışmadan elde edilen sonuçlar, öğretmen adaylarının çoğunluğunun (yaklaşık \%90) sıradan bir problem karşııında strateji belirleyip, belirledikleri bu stratejiyi ya da farklı bir stratejiyi uyguladıklarını göstermektedir. Ancak az sayıda da olsa herhangi bir çözüm yapamayan ya da yanlış çözüm yapan adaylar bulunmaktadır. Çözümün değerlendirilmesi aşamasında ise öğretmen adaylarının yarıdan azı (\%36) farklı stratejiyi kullanarak ikinci bir çözüm önerebilmişlerdir. Bu durum, Leikin ve Levav-Waynberg'in (2007) problemi birden fazla yolla çözmenin matematiksel düşünmeyi ve yaratıcılığı geliştirme ve keşfetmede etkili bir araç olabileceği düşüncesi dikkate alındığında, öğretmen adaylarının bu anlamdaki eksikliklerine dikkat çekmektedir. 
Çalışmadan elde edilen önemli sonuçlardan birisi, öğretmen adaylarının sınıf öğretmenliği yapacakları ve öğrencilerinin bilişsel gelişimlerinin somut işlemler döneminde olacak çocuklar olacağı düşünüldüğünde ilk çözümlerinde sadece \%4,42' sinin denklem kullanma stratejisini kullandığıdır. Bu sonuç Ulu'nun (2008) sınıf öğretmeni adaylarının denklem kullanma stratejisini tercih ettikleri sonucu ile farklılık göstermektedir. Ancak ikinci bir çözüm istendiğinde denklem kullanma stratejisinin kullanma sıklı̆ının $(\% 7,96)$ az da olsa arttğ̆ı da görülmektedir. Bu durumun ise farklı bir çözümü öngörecek bir strateji belirleyemediklerinden kaynaklandığı düşünülebilir. Ayrıca, bazı çözümlerinde de denklem kullanmamayı tercih etmek adına denklemdeki bilinmeyenleri somut nesnelerle görselleyip, strateji adını değiştirmeye çalışmışlardır. Reys ve Suydam (2014), problem çözme stratejilerinin kullanılmasında öğrencinin gelişim düzeyinin dikkate alınması gerektiğini belirtmektedir. Bu nedenle adayların her ne kadar bu stratejiyi tercih etmeseler bile yine de kullanma eğiliminde oldukları dair bu sonuçlar, bahsedilen uyarıya tekrar vurgu yapmaktadır.

Kullanılan stratejiler dikkate alındığında, bunların çoğunlukla tahmin-kontrol, sistematik liste yapma ve diyagram çizme gibi literatürde sıkça adı geçen stratejiler olduğu görülmektedir. Bu durum, Avcu (2012) ve Gürbüz ve Güder 'in (2016) ilköğretim matematik öğretmenleri ile yapttğı çalışmalar ve Pehlivan'ın (2011), orta öğretim matematik öğretmeni adayları ile yaptığı çalışmalarla benzer sonuçlar belirtmektedir. Reys ve Suydam'ın (2014) değişik stratejilerin öğrenilmesinin öğrencilerin karşılaşabilecekleri problemlerin çözümünde kolaylık sağlayacağı fikri düşünüldüğünde, öğretmen adaylarının farklı stratejileri geliştirmeye yönelik kazanımlarının artııımasının gerektiği görülmektedir. Zira yapılan çalışmalar (örneğin Altun, 2010; Altun, Bintaş, Yazgan ve Arslan, 2004; Altun, Dönmez, İnan, Taner ve Özdilek, 2001; Vershaffel, De Corte, Lasure, Vaerenbergh, Bogaerts ve Ratinckx, 1999; Yavuz, 2006; Yazgan ve Bintaş, 2005), problem çözme stratejisinin öğretimle geliştirilebileceğini vurgulamaktadır.

Elde edilen sonuçların ışı̆̆ında, öğretmen adaylarının yeni ve farklı stratejiler öğrenmeleri konusunda eksikliklerinin giderilmesi, ilkokul öğrencilerine yönelik stratejilerin kullanımı konusundaki alacakları eğitimlerin artırıması, farkı problemlerle karşılaşmaları için firsatların verilmesinin sınıf öğretmeni adaylarının problem çözme süreçlerine önemli katkılar sağlayacağı düşünülmektedir.

\section{Kaynakça}

Altun, M., Dönmez, N., İnan, H., Taner, M., \& Özdilek, Z. (2001). Alt yaş grubu çocukların problem çözme stratejileri ve bunlarla ilgili öğretmen ve müfettiş algıları. Uludağ Üniversitesi Eğitim Fakültesi Dergisi, 14(1), 211-230.

Altun, M., Bintaş, J., Yazgan, Y., \& Arslan, Ç. (2004). Illöğretim Çağındaki Çocuklarda Problem Çözme Gelişiminin Incelenmesi. Uludağ Üniversitesi, Bilimsel Araştırma Projeleri Birimi, Bursa.

Altun, M., Memnun, D. S., \& Yazgan, Y. (2007). Primary school teacher trainees' skills and opinions on solving non-routine mathematical problems. Elementary Education Online, 6(1), 127-143.

Altun, M. (2010). Eğitim fakülteleri ve sınıf öğretmenleri için matematik öğretimi. Bursa: Aktüel Alfa Akademi.

Avcu, S. (2012). Ilköğretim matematik öğretmen adaylarının matematiksel problem çözmede kullandıkları stratejilerin incelenmesi (Yayınlanmamış yüksek lisans tezi). Orta Doğu Teknik Üniversitesi, Ankara.

Aylar, E. (2017). Sınıf öğretmeni yetiştirme sürecinde problem çözmeye dair pedagojik alan bilgisine ilişkin çıkarımlar. Mersin Üniversitesi Eğitim Fakültesi Dergisi 13(2), 744-759.

Berg, B. L. (2001). Qualitative research methods for the social sciences. Boston: Allyn and Bacon.

Cai, J. (2003). Singaporean students' mathematical thinking in problem solving and problem posing: An exploratory study. International Journal of Mathematical Education in Science and Technology, 34(5), 719-737.

English, L. D., Jones, G. A., Tirosh, D., Lesh, R., \& Bartolini Bussi, M. G. (2002). Future issues and direction in international mathematics education research. In L. D. English (Ed.), Handbook of International Research in Mathematics Education (787-812). New Jersey: Lawrence Erlbaum Associates.

Fan, L., \& Zhu, Y. (2007). Representation of problem-solving procedures: A comparative look at China, Singapore, and US mathematics textbooks. Educational Studies in Mathematics, 66(1), 61-75.

Gümüş, F. Ö., \& Umay, A. (2017). Problem çözme stratejileri öğretiminin ilköğretim matematik öğretmen adaylarının kavramsal/işlemsel çözüm tercihlerine ve problem çözme performansına etkisi. ilköğretim Online, 16(2), 746-764.

Gürbüz, R., \& Güder, Y. (2016). Matematik öğretmenlerinin problem çözmede kullandıkları stratejiler. Ahi Evran Üniversitesi Kırşehir Eğitim Fakültesi Dergisi (KEFAD) 17(2), 371-386.

Hammerness, K., Darling-Hammond, L., \& Bransford, J. (2005). Preparing teachers for a changing world. What teachers should learn and be able to do. In L. Darling-Hammond and J. Bransford (Eds), How Teachers Learn and Develop (pp. 358-389), Jossey-Bass: Wiley.

Jonassen, D. H. (2000). Toward a design theory of problem solving. Educational Technology: Research and Development, 48 (4), $63-85$. Kılıç, Ç. (2014). Sınıf öğretmenlerinin problem kurmayı algılayış biçimlerinin belirlenmesi. Kastamonu Eğitim Dergisi, 22(1), $203-214$. 
Krulik, S., \& Rudnick, J. (1988). Problem solving: A handbook for elementary school teachers. Boston: Allyn and Bacon.

Leikin, R., \& Levav-Waynberg, A. (2007). Exploring mathematics teacher knowledge to explain the gap between theory-based recommendations and school practice in the use of connecting tasks. Educational Studies in Mathematics, 66(3), 349-371.

Milli Eğitim Bakanlığı [MEB]. (2008). Öğretmen yeterlikleri: öğretmenlik mesleği genel ve özel alan yeterlikleri. Ankara: Millî Eğitim Basımevi.

Milli Eğitim Bakanlığı [MEB]. (2015). Illkokul matematik dersi (1, 2, 3 ve 4. sınıflar) öğretim programı, Ankara: Milli Ĕgitim Basımevi.

Milli Eğitim Bakanlığı [MEB]. (2017). Matematik dersi öğretim programı (ilkokul ve ortaokul), Ankara: Milli Eğitim Basımevi.

National Council of Teachers of Mathematics [NCTM]. (1991). 1991-1992 Handbook: NCTM goals, leaders, and positions. Reston, VA: NCTM.

National Council of Teachers of Mathematics [NCTM]. (2000). Principles and standards for school mathematics. Reston, VA: NCTM.

Olkun, S., \& Toluk, Z. (2009). Ilköğretimde etkinlik temelli matematik öğretimi. Ankara: Maya Akademi.

Pehlivan, C. F. (2011). Matematik problemlerinin çözümünde öğretmen adaylarının kullandıkları stratejilerin ve gösterim şekillerinin analizi (Yayımlanmamış yüksek lisans tezi). Dokuz Eylül Üniversitesi, İzmir.

Polya, G. (1957). How to solve it? (2d ed.). New York: Anchor Books.

Posamentier, A. S., \& Krulik S. (2008). Problem-solving strategies for efficient and elegant solutions, grades 6-12: A research for the mathematics teacher. California: Corwin Press.

Reys, R. E., Lindquist, M., Lambdin, D. V., \& Smith, N. L. (2014). Helping children learn mathematics. NY: John Wiley \& Sons.

Ulu, M. (2008). Sınıf öğretmeni, sınıf öğretmeni adayı ve 5. sınıf öğrencilerinin dört işlem problemlerini çözmede kullandıkları stratejilerin karşılaştırılması (Yayınlanmamış yüksek lisans tezi). Kocatepe Üniversitesi, Afyon.

Verschaffel, L., De Corte, E., Lasure, S., Van Vaerenbergh, G., Bogaerts, H., \& Ratinckx, E. (1999). Learning to solve mathematical application problems: A design experiment with fifth graders. Mathematical Thinking and Learning, 1(3), 195- 229.

Yavuz, G. (2006). Dokuzuncu sınıf matematik dersinde problem çözme stratejileri strateji öğretiminin duyuşsal özellikler ve erişiye etkisi (Yayınlanmamış doktora tezi). Dokuz Eylül Üniversitesi, İzmir.

Yazgan, Y., \& Bintaş, J. (2005). illköğretim dördüncü ve beşinci sını öğrencilerinin problem çözme stratejilerini kullanabilme düzeyleri: Bir öğretim deneyi. Hacettepe Üniversitesi Eğitim Fakültesi Dergisi, 28, 210-218.

Yıldırım, A., \& Şimşek, H. (2006). Sosyal bilimlerde nitel araştırma yöntemleri. Ankara: Seçkin Yayıncllık.

Yin, R. K. (2003). Case study researches, design and methods ( $3^{\text {rd }}$ ed.). California: Sage Publications. 